\title{
BCG Identification by DNA Restriction Fragment Patterns
}

\author{
By DESMOND M. COLLINS* AND GEOFFREY W. DE LISLE \\ Central Animal Health Laboratory, Wallaceville Animal Research Centre, Upper Hutt, \\ New Zealand
}

(Received 29 December 1986)

\begin{abstract}
Seven daughter strains of BCG were characterized by restriction fragment analysis with the enzymes BstEII, PruII and Bc/I. Comparisons of fragment patterns confirmed that BCG is correctly classified as a Mycobacterium bovis variant and suggested that the Swedish strain is most closely related to the original BCG strain.
\end{abstract}

\section{INTRODUCTION}

Bacille Calmette Guérin (BCG) was established as an avirulent vaccination strain in 1921 after the original mycobacterial isolate had been subcultured on synthetic media 230 times at three-week intervals (Guérin, 1957). The original mycobacterial isolate was lost some years before 1921, and although it had supposedly come from a bovine source its identity as a member of the species Mycobacterium bovis has been doubted (Grange et al., 1983). Current strains of BCG are classified as $M$. botis variants but it has been suggested on phenotypic evidence that they might better be regarded as strains of Mycobacterium tuberculosis or as a separate group within the tuberculosis complex (Grange et al., 1983). Virulence of tuberculosis is still poorly understood and the relationship of the original and current BCG strains to each other and to virulent strains of the tuberculosis complex is of continuing interest.

It has been widely accepted for many years that BCG vaccination affords a useful degree of protection against tuberculosis, particularly in children (Grange et al., 1983). However, the effectiveness of vaccination measured in large controlled studies has varied from 0 to $80 \%$ (Chaparas, 1982). Several possible explanations have been advanced to explain this variation, the hypothesis invoking differences in the immunogenic properties of different BCG daughter strains receiving much attention (ten Dam \& Pio, 1982). Since 1921, strains of BCG have been established in many different countries and these daughter strains now differ considerably in: growth both in vitro (Osborne, 1983) and in vivo (Ladefoged et al., 1976; Sher et al., 1973), phage susceptibility (Mankiewicz \& Liivak, 1977), antigen production (Harboe \& Nagai, 1984), and other characteristics (International Union Against Tuberculosis, 1978; Minnikin et al., 1984). It is generally accepted that these differences result from genetic changes but the extent of the changes is unknown. A clear need exists to characterize these daughter strains more adequately.

Recently, we developed a restriction fragment analysis technique which was sufficiently sensitive to distinguish between the closely related species of the tuberculosis complex (Mycobacterium microti, M. africanum, M. tuberculosis and M. bovis) (Collins \& de Lisle, 1985) and also between strains within the species $M$. tuberculosis (Collins \& de Lisle, 1984) and $M$. botis (Collins et al., 1986). In the course of that work we noted that patterns given by a single strain of BCG were similar to those of $M$. bovis strains (Collins \& de Lisle, 1985). As a consequence we obtained seven daughter strains of BCG and subjected them to restriction fragment analysis. 


\section{METHODS}

The BCG strains studied were BCG Copenhagen (Glaxo), BCG Danish (seed-lot 1331), BCG Japanese (strain 172), BCG French (Pasteur seed-lot 1173 P2), BCG Russian, BCG Swedish and BCG Moreau. DNA was prepared from cultures of each of the strains grown in Tween-albumin broth as described for $M$. bovis (Collins \& de Lisle, 1984). Samples $(4 \mu \mathrm{g}$ ) of DNA were digested separately with the restriction enzymes $B s t$ EII, $P v u I I$ and $B c l I$ and the fragments were separated by high-resolution electrophoresis as described previously (Collins $\&$ de Lisle, 1985).

\section{RESULTS AND DISCUSSION}

The most notable feature of the DNA fragment patterns (Fig. 1) was the high degree of similarity for all the strains. Although the differences detected between the strains were minor they were reproducible; when DNA was prepared a second time from recultured strains and then digested with the same enzymes, patterns identical to the original patterns were obtained. Comparison of these patterns with those from the four species of the tuberculosis complex (Collins \& de Lisle, 1984, 1985; Collins et al., 1986; and our unpublished patterns) shows that the BCG strains are most closely related to the species $M$. bovis. Certain combinations of fragment lines appear unique to the BCG strains but the overall number of fragment differences between BCG patterns and some of the $M$. bovis patterns is no more than that which occurs between the $M$. bovis strains themselves. Restriction fragment analysis thus provides a new method for identifying BCG strains and also confirms the classification of these strains as members of the $M$. bovis species. This contrasts with the suggestion based on selected phenotypic tests that BCG is more similar to M. tuberculosis than to M. bovis (Magnusson, 1961; Wietan et al., 1981). However, these phenotypic approaches use a relatively small number of characteristics compared to restriction fragment analysis, which is based on the distribution of a large number of restriction sites spread throughout the genome.

Combination of the results from BstEII and either of the other two enzymes separated the BCG strains into six distinct entities; none of the enzymes differentiated the Danish and Copenhagen strains. At those few fragment positions at which differences were observed (indicated by arrowheads in Fig. 1) the patterns of the majority of the BCG strains were identical. Thus for each restriction enzyme there was a consensus pattern. The only strain whose patterns were identical with the consensus patterns of all three enzymes was BCG Swedish. BCG Japanese was almost identical and differed at only one fragment line with the enzyme BstEII. If, as appears reasonable, the strains studied here are an acceptably broad selection of the different BCG daughter strains, then the consensus patterns of the current strains probably bear the closest resemblance to the original BCG strain of 1921. The similarity of BCG Swedish to the original BCG strain is also supported by historical evidence. The Swedish strain was established only five years after the original BCG strain and, unlike other daughter strains, was maintained until the modern era by Calmette's original cultivation techniques (Lind, 1983).

It is not known whether the fragment differences between strains are directly linked to the genetic elements which determine the phenotypic differences of the daughter strains. However, the two groups (Copenhagen, Danish, French; and Swedish, Russian, Japanese, Moreau) into which the strains are separated by the fragment line differences indicated on Fig. $1(a)$ by circled arrowheads agree with those determined on the basis of mycolic acid patterns (Minnikin et al., 1984 ) and production of specific protein antigen (Harboe \& Nagai, 1984). Detailed investigation of the function of the genetic sequences surrounding the BstEII recognition site which accounts for this pattern difference would be required to establish any linkage with these phenotypic differences. Even if a close linkage does not exist, restriction fragment analysis provides a useful method for identifying BCG daughter strains and may be used as a screening test to monitor for possible future changes in these strains.

We thank Mogens Magnusson, Statens Seruminstitut, Copenhagen, Denmark, for providing the BCG daughter strains. 


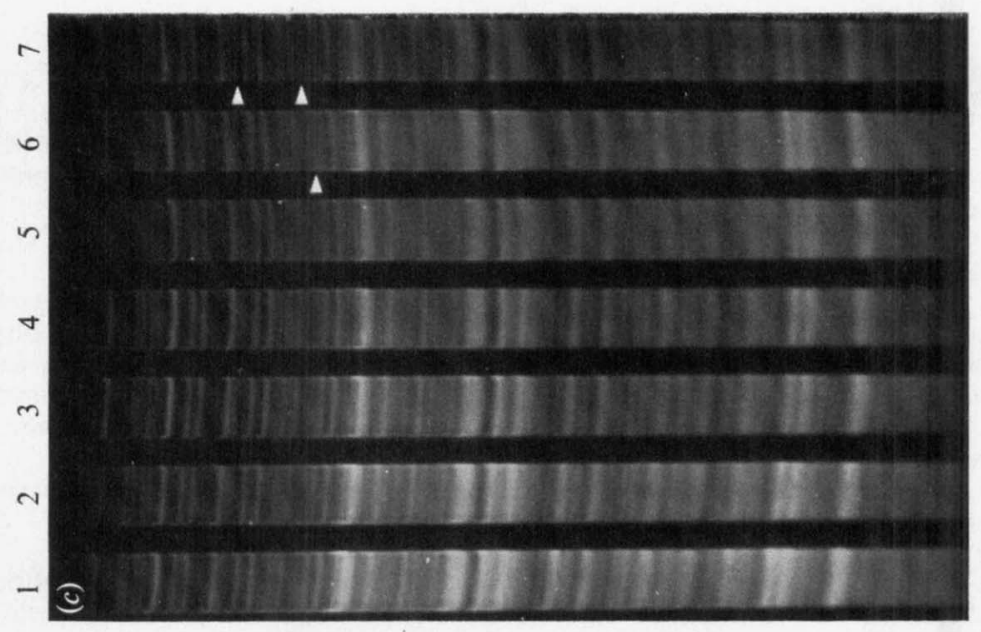

藏苋

뒁

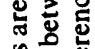

萢

政

要

등

氙

응

동

ऽ.

동

要要

ธ를.

远要

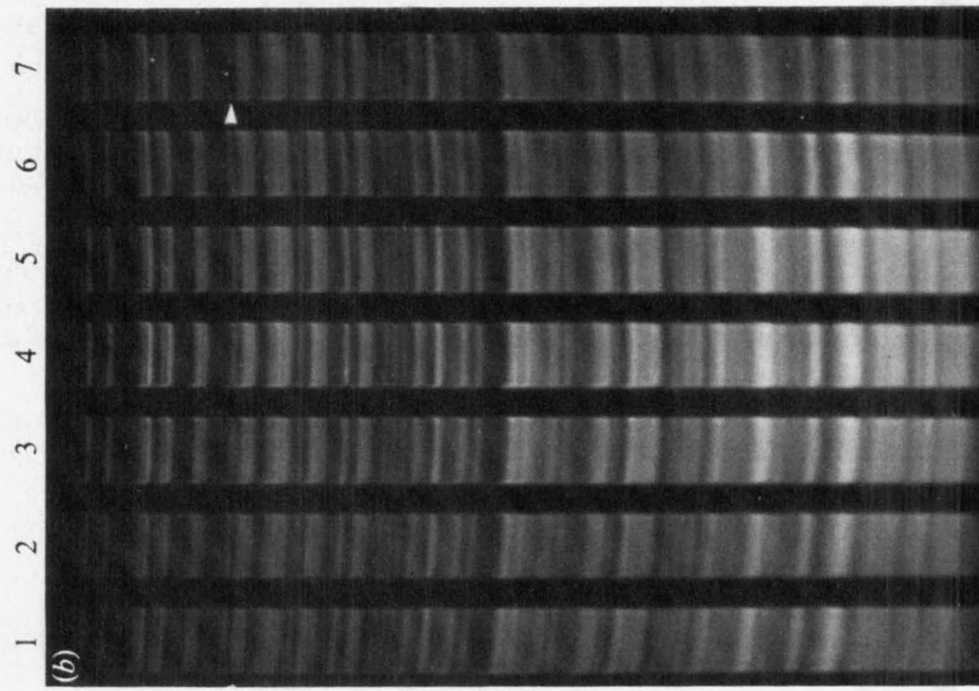

उड्ड

范灵

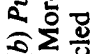

$=6$

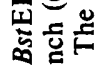

氙密

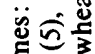

융

政

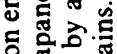

矛氙

宅导

西

동.

离岕

的的

क人

兽战

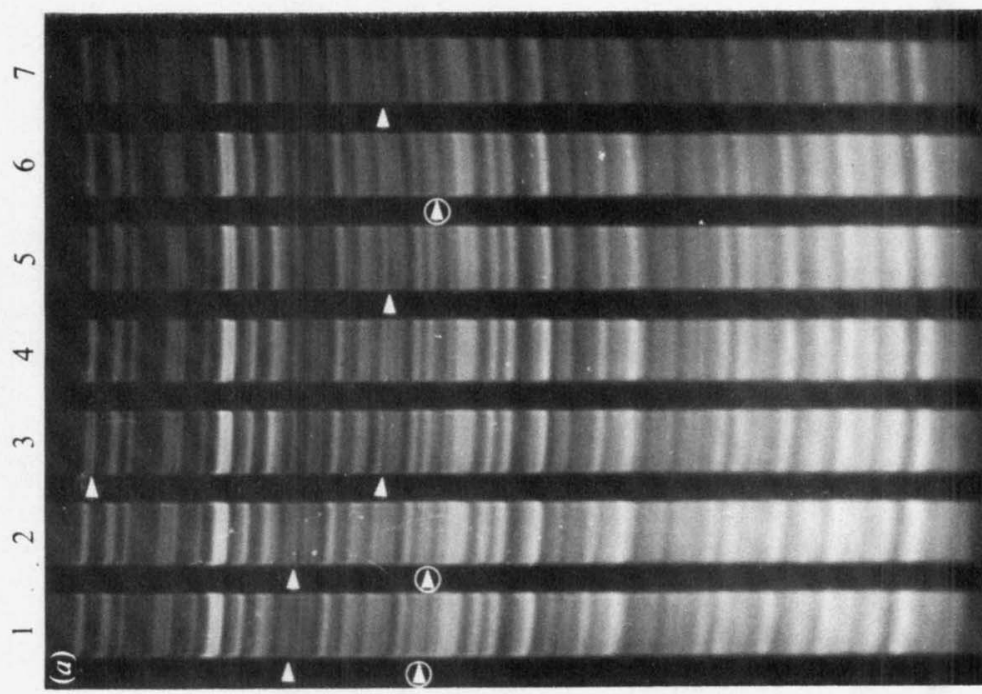

䯄 政

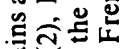
현 क 品入 을 志通的 응 हू है 五政 政 를등 Eด 密范心 $\leq$ 형요

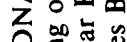
들 으응을 웡 


\section{REFERENCES}

Chaparas, S. D. (1982). Immunity in tuberculosis. Bulletin of the World Health Organization 60, 447462.

Collins, D. M. \& DE Lisle, G. W. (1984). DNA restriction endonuclease analysis of Mycobacterium tuberculosis and Mycobacterium bovis BCG. Journal of General Microbiology 130, 1019-1021.

Collins, D. M. \& DE Lisle, G. W. (1985). DNA restriction endonuclease analysis of Mycobacterium bovis and other members of the tuberculosis complex. Journal of Clinical Microbiology 21, 562-564.

Collins, D. M., de Lisle, G. W. \& Gabric, D. M. (1986). Geographic distribution of restriction types of Mycobacterium bovis isolates from brush-tailed possums (Trichosurus vulpecula) in New Zealand. Journal of Hygiene 96, 431-438.

TEN DAM, H. G. \& PIO, A. (1982). Pathogenesis of tuberculosis and effectiveness of BCG vaccination. Tubercle 63, 225-233.

Grange, J. M., Gibson, J., Osborne, T. W., Collins, C. H. \& YATES, M. D. (1983). What is BCG? Tubercle 64, 129-139.

GUÉRIN, C. (1957). The history of BCG: early history. In BCG Vaccination against Tuberculosis, pp. 48-53. Edited by S. R. Rosenthal. London: J \& A. Churchill.

HaRboe, M. \& NaGaI, S. (1984). MPB70, a unique antigen of Mycobacterium bovis BCG. American Review of Respiratory Diseases 129, 444-452.

INTERNATIONAL UNION AGAINST TUBERCULOSIS (1978). Phenotypes of BCG-vaccines seed lot strains: results of an international cooperative study. Tubercle 59, 139-142.
LAdefoged, A., Bunch-Christensen, K. \& Guld, J. (1976). Tuberculin sensitivity in guinea-pigs after vaccination with varying doses of BCG of 12 different strains. Bulletin of the World Health Organization 53, 435-443.

LIND, A. (1983). The Swedish strain of BCG. Tubercle 64, 233-234.

Magnusson, M. (1961). Specificity of mycobacterial sensitins. 1. Studies in guinea pigs with purified tuberculin prepared from mammalian and avian tubercle bacilli, Mycobacterium balnei and other acid fast bacilli. American Review of Respiratory Diseases 83, 57-68.

Mankiewicz, E. \& Lilvak, M. (1977). Phage types of Mycobacterium bovis, substrains of BCG. Canadian Journal of Microbiology 23, 818-823.

Minnikin, D. E., Parlett, J. H., Magnusson, M., RIDELL, M. \& LIND, A. (1984). Mycolic acid patterns of representatives of Mycobacterium bovis BCG. Journal of General Microbiology 130, 2733-2736.

OsBorNe, T. W. (1983). Changes in BCG strains. Tubercle 64, 1-13.

Sher, N. A., Chaparas, S. D., Pearson, J. \& ChIRIgos, M. (1973). Virulence of six strains of Mycobacterium bovis (BCG) in mice. Infection and Immunity 8, 736-742.

Wietan, G., Haverkamp, J., Meuzelaar, H. L. C., ENGel, H. W. B. \& Berwald, L. G. (1981). Pyrolysis mass spectrometry: a new method to differentiate between the mycobacteria of the "tuberculosis complex' and other mycobacteria. Journal of General Microbiology 122, 109-118. 